\title{
USE OF LUMBAR PUNCTURE FOR FIRST EPISODE OF FEBRILE SEIZURE AMONG CHILDREN 6 MONTHS TO 18 MONTHS OF AGE: A CROSS SECTIONAL STUDY
}

\author{
Kayastha $\mathrm{N}^{1^{*}}$, Rai $G K^{2}$, Karki $\mathrm{S}^{3}$
}

\section{Affiliation}

1. Lecturer, Department of Pediatrics, Karnali Academy of Health Sciences.

2. Professor, Department of Pediatrics, Kanti Childrens' Hospital, Kathmandu.

3. Assistant Professor, Department of Pediatrics, Kanti Childrens' Hospital, Kathmandu.

\section{ARTICLE INFO}

\section{Article History}

Received : 05 November, 2018

Accepted : 22 August, 2018

Published : 31 August, 2018

C Authors retain copyright and grant the journal right of first publication with the work simultaneously licensed under Creative Commons Attribution License CC - BY 4.0 that allows others to share the work with an acknowledgment of the work's authorship and initial publication in this journal.

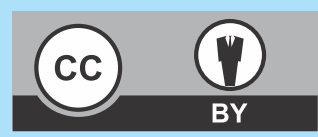

ORA 63

DOI: http://dx.doi.org/10.3126/bjhs.v3i2.20933

\author{
* Corresponding Author \\ Dr. Nirajana Kayastha \\ Lecturer \\ Department of Pediatrics \\ Karnali Academy of Health Sciences, Jumla \\ Email: nirajanakayastha@gmail.com \\ ORCID: https://orchid.org/0000-0003-4449-8499
}

\section{Citation}

Kayastha N, Rai GK, Karki S. Use of Lumbar Puncture for First Episode of Febrile Seizure among Children 6 months to 18 months of Age. BJHS 2018;3(2)6:399-402.

\section{ABSTRACT}

\section{Introduction}

Febrile seizure accounts for the majority cases of the pediatric seizure. Fever with seizure can be either due to febrile seizure or underlying serious infection as meningitis. As seizure may be the only manifestation of meningitis it is important to rule out meningitis in children presenting with fever and seizure.

\section{Objective}

The objective of this study was to determine the incidence of meningitis among children aged 6 to 18 months presenting with first episode of febrile seizure.

\section{Methodology}

A prospective observational study was conducted among 94 children with first episode of febrile seizure presenting to the emergency and observation wards of Kanti Childrens' Hospital and subjected to lumbar puncture (LP) as per the American Academy of Pediatrics (AAP) recommendations. The proportion of children with meningitis and no meningitis among the study population was determined, clinical characteristics were compared among these groups and the incidence of meningitis in simple febrile seizure and complex febrile seizure was calculated. The collected data was analysed using SPSS.

\section{Results}

Twenty (21.3\%) cases were diagnosed with meningitis among 94 children enrolled in our study. Meningitis was detected in $38.1 \%$ of the cases of complex febrile seizure and $7.7 \%$ of cases of simple febrile seizure. In the age group 6 to 12 months, $11(17.4 \%)$ had meningitis while in 12 to 18 months of age, $9(29 \%)$ were detected with meningitis. Meningitis was 7.38 times more likely in cases presenting with complex febrile seizure than simple febrile seizure $(\mathrm{OR}=7.58 ; 95 \% \mathrm{Cl} 2.24-24.4 ; \mathrm{p}<0.001)$. Regarding the clinical characteristics, vomiting, fever of more than 48 hours duration prior to onset of seizure, impaired consciousness and complex features of seizure were found to be significantly associated with meningitis in our study.

\section{Conclusion}

The probability of meningitis among children aged 6 to 18 months presenting with first episode of febrile seizure episode is high. In febrile convulsing children less than 18 months of age, meningitis should be considered even in the absence of signs of meningeal irritation .

\section{KEY WORDS}

Febrile seizure, lumbar puncture, meningitis 


\section{INTRODUCTION}

Febrile seizure is the most common form of childhood seizure. Febrile seizure is seizure that occurs between 6 months to 5 years of age with a temperature of 38 degrees centigrade or higher that is not the result of CNS infection or metabolic imbalance that occur in the absence of history of prior afebrile seizure. ${ }^{1}$ Febrile seizure can be classified as either simple or complex. A simple febrile seizure is primarily generalized, usually tonic-clonic attack associated with fever, lasting for a maximum of 15 minutes and not recurrent within a 24 hours period. Complex febrile seizure is more prolonged (>15 $\mathrm{min}$ ), is focal and recurs within 24 hours.

Febrile seizure accounts for 1-5\% of emergency department visits. ${ }^{2,3}$ The precise annual incidence of febrile seizure worldwide is not known. The incidence varies among different regions. In western Europe and USA the incidence is reported to be $2-5 \%$ whereas it is between $5-10 \%$ in India, $8.8 \%$ in Japan, $14 \%$ in Guam, $0.5-5 \%$ in China and $6.6 \%$ in Nepal. ${ }^{4 \cdot 6}$

In May 1996, recommendations were laid down by AAP regarding evaluation of children with the first episode of febrile seizure who present within 12 hours after the seizure. This guideline strongly recommended LP in children less than 1 year of age and considered in children between 12 to 18 months for diagnosing meningitis via cerebrospinal fluid (CSF) analysis. These recommendations were based on the knowledge that seizure is a common presenting symptom of bacterial meningitis and clinical assessment of children at this age for signs of meningitis can be difficult. ${ }^{8}$ However, in 2011 AAP updated their guideline recommending LP in any child whose history or examination suggests the presence of meningitis or intracranial infection. The guideline states that in any infant between 6 and 12 months of age LP is an option when the child is considered deficient in Haemophilus influenza type $b$ (Hib) or Streptococcus pneumonia immunization or when immunization status cannot be determined and it is an option in child who is pretreated with antibiotics as antibiotic treatment can mask signs and symptoms of meningitis. ${ }^{7}$

Meningitis is a major cause of childhood morbidity and mortality. Early detection and treatment are important to reduce the chances of adverse neurological outcome and death associated with it. The probability of bacterial meningitis in children with fever and seizure varies from $0.6 \%$ to $6.7 \%{ }^{9}$

Although there exist data regarding the yield of lumbar puncture among children with first episode of febrile seizure, the studies reflects a variable prevalence of meningitis. However only a few data exist regarding our country targeting children 6 to 18 months of age. Thus this study aims to evaluate the importance of lumbar puncture as this group has been identified as clinically difficult to assess for bacterial meningitis and meningeal signs are not always present.

\section{METHODOLOGY}

This was a hospital based prospective observational study which was conducted at the emergency and observation wards of Kanti Childrens' Hospital from November 2013 till October 2014.The inclusion criteria included all children 6 to 18 months of age with the first episode of febrile seizure who presented to the emergency and observation ward within 12 hours after the seizure. Those diagnosed with previous history of seizure disorder, chronic illness, trauma, neurosurgical intervention and critically ill children were excluded from the study. After initial stabilisation of the children, detailed history was taken and examination done. Children were considered febrile if their axillary temperature exceeded $100.4^{\circ} \mathrm{F}$. Investigations were sent to determine the focus of infection. After informed and written consent LP was done according to the AAP guidelines. The children were then observed for at least 12 hours. The proportion of children with meningitis and no meningitis among the study population was determined based on LP reports and the incidence of meningitis in simple febrile seizure and complex febrile seizure was calculated. Meningitis was considered in a child if he/she had CSF count $>5$ cells $/ \mathrm{mm}^{3}$, protein $>40 \mathrm{mg} / \mathrm{dl}$ and sugar $<2 / 3^{\text {rd }}$ of blood sugar or gram stain positive for bacteria and/or positive CSF culture. Seizure characteristics as type, duration, character, interval between fever and seizure, number of seizure episodes and postictal drowsiness, the presence of meningeal signs and the presenting symptoms and signs were compared between the meningitis and no meningitis group. The causes attributable to fever in febrile seizure were also identified and final diagnosis assigned after complete history, examination and investigation. Data entry and analysis were done by using SPSS version 16. Categorical data was analyzed by chi-square test. $P$ value of $<0.05$ was considered significant.

\section{RESULT}

During the study period of one year, 94 children who met the inclusion criteria were enrolled in the study. The age group was categorised into two groups: 6 to 12 months and 12 to 18 months as per the AAP practice parameters. The study group 6 to 12 months included 63 (67.1\%) children whereas, 12 to 18 months group included 31 (33.9\%) children. Almost two third of the cases (67\%) of febrile seizure were below 12 months of age. There was male predominance in the study population with the male:female ratio of 1.8:1. Of the total cases, majority of the children (55\%) presented with simple febrile seizure. Among the patients with febrile seizure, almost one fifth (21.3\%) had meningitis (Figure 1). Meningitis was more commonly detected in children with complex febrile seizure than simple febrile seizure (Table 1). Significant association was observed in the occurrence of meningitis and the type of febrile seizure $(p<0.001)$. Among 20 cases of meningitis, there was a total of 11 (54.5\%) cases in the age group of 6 to 12 months and 9 ( $45.5 \%$ ) cases in the age group of 12 to 18 months so the higher incidence was seen in children less than 12 months(Figure 2). Regarding clinical characteristics 
statistical corelation was found between duration of fever of more than 48 hours before the presentation of seizure and meningitis $(p=0.007)$. Vomiting $(p=0.009)$ and impaired consciousness $(p=0.031)$ were found to be significantly associated with meningitis. The mean temperature recorded in the meningitis group was $102.2 \pm 0.96^{\circ} \mathrm{F}$ S.D. whereas it was $101.5 \pm 1.01^{\circ}$.F S.D. which was statistically significant $(p=0.004)$. The most common cause of fever in febrile seizure was URTI (27.7\%) followed by pneumonia (18\%) and bronchiolitis (16\%) (Table 2).

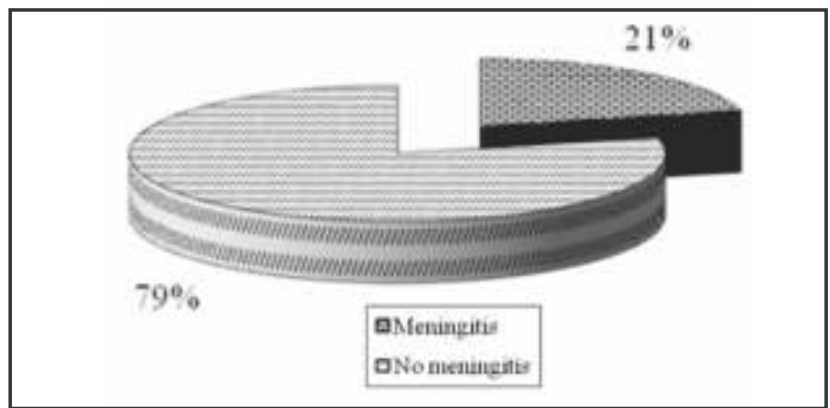

Figure 1: Proportion of study population with meningitis $(n=94)$

\begin{tabular}{|c|c|c|c|c|c|}
\hline $\begin{array}{c}\text { Type of } \\
\text { febrile Seizure }\end{array}$ & Meningitis & $\begin{array}{l}\text { No } \\
\text { meningitis }\end{array}$ & P-value & $\begin{array}{l}\text { Odds } \\
\text { Ratio }\end{array}$ & $95 \% \mathrm{Cl}$ \\
\hline Complex & $16(38.1 \%)$ & $26(61.9 \%)$ & $<0.001$ & 7.38 & $2.24-24.4$ \\
\hline Simple & $4(7.7 \%)$ & $48(92.3 \%)$ & & & \\
\hline
\end{tabular}

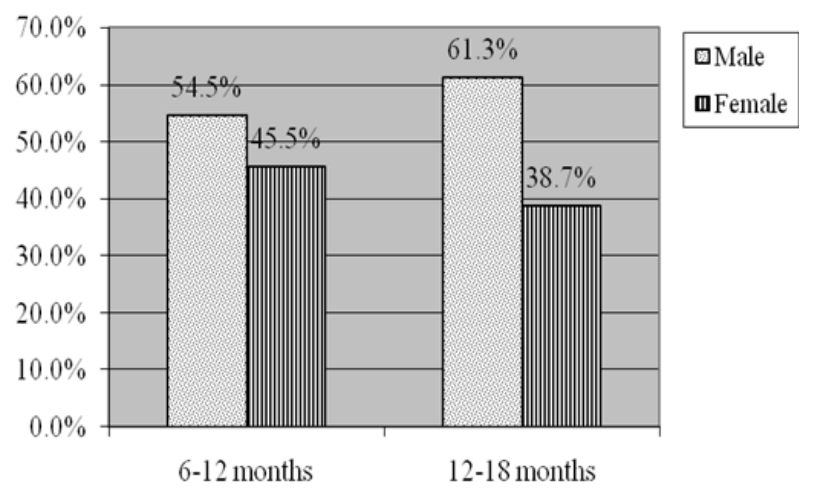

Figure 2: Distribution of cases of meningitis according to age and $\operatorname{sex}(n=20)$

Table 2: Causes of fever in the study population

\begin{tabular}{|l|c|c|}
\hline Cause of fever* & Frequency & \% \\
\hline URTI & 26 & 27.7 \\
\hline Pneumonia & 17 & 18 \\
\hline Bronchiolitis & 15 & 16 \\
\hline AGE & 14 & 14.8 \\
\hline UTI & 11 & 11.7 \\
\hline Otitis media & 6 & 6.5 \\
\hline Meningitis & 20 & 21.3 \\
\hline
\end{tabular}

*some patients had more than one diagnoses

\section{DISCUSSION}

Among 94 children enrolled in our study, 20 (21.3\%) children had meningitis showing that almost one fifth of the children presenting with febrile seizure had meningitis. Similar high incidence of meningitis was detected among children between 6 to 18 months in study done by Shrestha et al in Nepal and Owusu-Oforiet al in Ghana in which the incidence of meningitis was $20.3 \%$ and $10.2 \%$ respectively. ${ }^{10,11}$ But it is much higher as compared to study done by Ehsanipour et al at Hazrat Rasoul Hospital, Iran in which meningitis was reported in $3.6 \%$ of the cases. ${ }^{12}$ Similar low incidence of meningitis (3.8\%) was observed in a cross sectional study conducted by Watemberg et al in Israel (3.8\%), Ghotbi et al (4.7\%) and Casasoprana et al(1.9\%). ${ }^{13-15}$ The incidence of meningitis was comparatively higher in our study than others. It may be because about a large proportion i.e. $45.7 \%$ of the cases in our study presented with complex febrile seizure which poses a greater risk of meningitis than simple febrile seizure. Meningitis was detected in $38.1 \%$ of the cases with complex febrile seizure compared to $7.7 \%$ of the cases with simple febrile seizure $(p<0.001)$. Significant difference is observed in the incidence of meningitis among children with simple and complex febrile seizure which is comparable to other studies. A study done by Tavasoli et al in Ali Asghar Children Hospital, Iran showed meningitis to be associated more with complex febrile seizure than simple febrile seizure ( $84.2 \%$ Vs $15.8 \%$, $p<0.001) .{ }^{16}$ Similarly in other studies conducted by Casasoprana et al and Batra et al, the incidence of meningitis was higher in complex febrile seizure than simple febrile seizure (13\% Vs $0 \%$ and $44.81 \%$ Vs $0.86 \%$ respectively). ${ }^{15,17}$

The mean age of presentation of meningitis was $11.1 \pm 4.25$ months S.D. In our study younger age is found to be associated with higher risk of meningitis. The majority of children with meningitis were less than 12 months. In 6 to 12 months age group, 63 cases (67.1\%) had meningitis as compared to 31 cases (32.1\%) in 12 to 18 months age group. Significant difference is observed in the incidence of meningitis among the children less than and over 12 months of age in other studies too. ${ }^{10,11,17}$

The mean temperature recorded in the meningitis group was $102.2 \pm 0.96^{\circ} \mathrm{F} \mathrm{S.D}$ and no meningitis group was $101 \pm 1.01^{\circ} \mathrm{F} \mathrm{S}$.D. which is statistically significant $(p=0.004)$. We have found in our study that febrile convulsing children with meningitis have proportionately higher grade fever than children with no meningitis. Similar observations were made by Ghotbi et al and Singh et al who considered high grade fever as independent predictor of meningitis among children with first febrile convulsion. ${ }^{14,18}$

Regarding clinical characteristics statistical corelation was found between duration of fever of more than 48 hours before the onset of seizureand meningitis $(p=0.007)$. Meningitis was detected in 10 cases (50\%) who presented with fever of more than 48 hours duration. Similar finding was observed in study done by Al-Eissa et al in which meningitis most commonly occurred with fever of this duration. ${ }^{19}$ In our study, patients with meningitis had significantly greater frequency of impaired consciousness which was statistically significant $(p=0.0001)$. It was 
comparable with the studies conducted by Casasoprana et al, Tavasoli et al and Al-Eissa Y et al. and in which impaired consciousness was considered to be a significant risk factor for meningitis. ${ }^{15,16,19}$

Regarding the etiology of the febrile illness leading to the seizure, URTI (27.6\%) followed by pneumonia (18\%) and bronchiolitis (11.7\%) were the common causes of fever in our study. URTI was the commonest cause of fever in children in this study which was similar to other studies. ${ }^{12,17,20}$

\section{CONCLUSION}

In this prospective observational study, the incidence of meningitis was found to be high (21.3\%) among children aged 6 to 18 months presenting with their first episode of febrile seizure. Meningitis was more commonly associated with complex febrile seizure than simple febrile seizure. Children with complex febrile seizure were 7.38 times more likely to have meningitis in comparison of simple febrile seizure. Though it is difficult to diagnose younger children with meningitis clinically as children less than 18 months usually lack signs of meningeal irritation, certain characteristics as vomiting, complex features of seizure, delayed seizure i.e. more than 48 hours of onset of seizure and impaired consciousness were found to be significantly associated with meningitis.

\section{RECOMMENDATIONS}

In the view of high probability of meningitis among children aged 6 to 18 months presenting with first episode of febrile seizure, lumbar puncture needs to be considered. In febrile convulsing children less than 18 months meningitis should be considered even in the absence of signs of meningeal irritation.

\section{LIMITATION}

An important limitation to our study is the small number of patients. The other limitation include shorter period of study. Our study reflects data from one center and may not be represent that of other centers across the country so as, given that our study was conducted in one study center with a small sample size, a multicenter trial would be necessary to determine the incidence of meningitis in patients aged 6 to 18 months.

\section{ACKNOWLEDGMENT}

I would like to acknowledge Prof. Dr Ganesh K. Rai and Dr. Subhana Karki for their constant support and proper guidance for the completion of this research work.

\section{CONFLICT OF INTEREST}

We declare no conflict of interest.

\section{FINANCIAL DISCLOSURE}

None

\section{REFERENCES}

1. Mohamad A. Mikati. Febrile seizure. In: Behrman RE, Jenson HB. Nelson textbook of Pediatrics. $19^{\text {th }} \quad$ Ed. Saunders press; 2017-9.

2. Pallin DJ, Goldstein JN, Moussally JS, Green AR, Pelletire AJ. Seizure visits in US emergency departments: epidemiology and potential disparities in care. Int J Emerg Med. 2008 Jun;1(2):97-105

3. Armon K, Stephenson T, Macfaul R, Eccleston P, Werneke U, Smith S. Determining the common medical presenting problems to an accident and emergency department. Arch Dis Child. 2001 May;84(5): 390-92.

4. Hauser WA. The prevalance and incidence of convulsive disorders in children. Epilepsia 1994;35(2):1-6.

5. Chung B, Wat LC, Wong V. Febrile seizure in southern Chinese children :incidence and recurrence. Pediatr Neurol. 2006 Feb;34(2):121-6.

6. Ojha AR, Arya UR. Leucocytosis in febrile seizure. J. NepPediatr Soc. 2011;31(3):181-91.

7. American Academy of Pediatrics. Subcommittee on Febrile Seizure. Febrile seizure: guidelines of the neurodiagnositc evaluation of the child with simple febrile seizure. Pediatrics. 2011 Feb;127(2): 389-94.

8. Akpede GO, Sykes RM. Convulsions with fever as a presenting feature of bacterial meningitis among preschool children in developing countries. Dev Med Child Neurol. 1992 Jun;34(6):524-9.

9. Carroll W, Brookfield D. Lumbar puncture following febrile convulsion. Arch Dis Child. 2002 Sep;87(3):238-40.

10. Shrestha D, Dhakal AK, Shakya H, Shakya A, Shah SC. Clinical characteristics of children with febrile seizure. J Nepal Health Res Counc. 2014 Sep;12(28):162-6.

11. Owusu-Ofori A, Agbenyega T, Ansong D, Scheld WM. Routine lumbar puncture in children with febrile seizures in Ghana: Should it continue? Int J Infect Dis. 2004 Nov;8(6):353-61.
12. Ehsanipour F, Khodapanahandeh F, Aslani Z. The prevalence of meningitis in children with febrile seizure hospitalized at HazratRasoul Hospital. RJMS. 2005;11(44):907-912.

13. Watemberg N, Sarouk I, Fainmesser P. Acute meningitis among infants and toddlers with febrile seizures: time for a reappraisal of the value of a lumbar puncture. IMAJ. 2012 Sep;12:547-9

14. Ghotbi F, Shiva F. An assessment of the necessity of lumbar puncture in children with fever and seizure. J Pak Med Assoc. 2009 May;59(5):292-5.

15. Casasoprana A, Hachon C, Claudet I, Grauieau E. Value of lumbar puncture after first febrile seizure in children aged less than 18 months. Arch Pediatr. 2013 Jun;20(6):594-600.

16. Tavasoli A, Afsharkhas L, Edraki A. Frequency of meningitis in children presenting with febrile seizure in Ali-Asghar Children's Hospital. Iran J Child Neurol 2014; 8(4):51-56.

17. Batra P, Gupta S, Gomber S, Saha A. Predictors of meningitis in children presenting with first febrile seizure. Pediatr Neurol. 2011 Jan;44(1):35-9.

18. Singh A, Silayach J, Gathwala G, Kaushik JS. Predictors of acute bacterial meningitis among children with a first episode of febrile convulsion from Northern India: A prospective study. Ann Trop Med Public Health 2014;7:9-13.

19. Al-Eissa YA. Lumbar puncture in the clinical evaluation of children with seizure associated with fever. PediatrEmerg Care. 1995 Dec;11(6):347-50.

20. Tinsa F, EL Gharbi, Ncibi N, Aissa W, Zouari B. Role of lumbar puncture for febrile seizure among infants under one year old. Tunis Med. 2010 Mar;88(3):178-183 